\title{
St. Andrew's Ambulance Association experience at Ibrox and Hampden Parks
}

\author{
R. Scott MD, FRCS(Glas), FRCS(Ed) ${ }^{1}$, N. Burns BEM ${ }^{2}$, G. McIlwraith AIM, AWeldI, \\ MInstNDT ${ }^{2}$, Isobel Kirkwood MB ChB, FCAnaes ${ }^{1}$ and A. Petrie QPM, SBStJ ${ }^{1}$ \\ ${ }^{1}$ Members of Council, St. Andrew's Ambulance Association \\ ${ }^{2}$ Nominated Officers
}

Recent major accidents at football grounds have greatly increased government and public awareness of the potentially lethal environment of soccer grounds in the UK. In the final recommendations of the official report on the Hillsborough disaster it is stated that regular liaison of the emergency services, specifically police, fire and ambulance, at designated sports grounds is extremely important. In his report ${ }^{1}$, Lord Taylor does not include the first aiders in this particular context, but in a subsequent paragraph he advocates the presence of first aiders at a rate of 1 per 1000 spectators (Recommendation 64).

First aiders at football grounds are present on a voluntary basis and are organized by their parent organizations, namely St. Andrew's Ambulance Association in Scotland, St. John Ambulance Association in England, Wales and Northern Ireland and the British Red Cross in all four countries. It is the first aiders who initiate the primary medical response in the event of a major incident, as was clearly seen on the television recordings of the Hillsborough disaster.

\section{Training and recruitment of first aid personnel}

Under the auspices of all three parent organizations the first aiders undergo a series of lectures and practical demonstrations by first aid instructors and by members of the medical profession. After passing the necessary examination at the end of the course, these lay persons are invited to become full members of a corps company or its equivalent where they are taught procedures of transportation of casualties, advanced techniques, and response of first aiders acting in partnership with other emergency workers. In addition, they are required to update their first aid certificates regularly to ensure that they are aware of new equipment and that their knowledge is satisfactory and current.

Address for correspondence: Dr R. Scott, Department of Urology and Male Infertility, Royal Infirmary, 16 Alexandra Parade,

Glasgow G31 2ER, UK

(C) 1991 Butterworth-Heinemann Ltd.

0306-3674/91/030134-04
Those who volunteer to serve at football matches may work in the first aid room - often staffed by lady members of the various corps companies or members of the home nursing sections of the associations. The majority of the support teams attend within the ground. During the season and in the off-season, regular exercises are carried out by St. Andrew's Ambulance Association in empty stadia, where groups of first aiders practise a variety of techniques, including such tricky procedures as the removal of unconscious casualties from seats in the stands, or they learn how to deal with major accidents such as crushing or staircase accidents - which Lord Taylor has pointed out are a continuing source of concern even in the most modern stadia.

\section{Ibrox and Hampden football stadia}

Glasgow has several large football stadia, including Ibrox Stadium, home of Glasgow Rangers Football Club, which met with favour from Lord Justice Taylor, and Hampden Park, the national ground. (When Hampden is not in use for major international matches it is used for second division games by Queen's Park Football Club; these are not of concern in this report.)

Ibrox Stadium has been extensively modernized. With the exception of one small area (soon to be removed) which allows approximately 5000 to stand, spectators are all seated. The average crowd at Ibrox for Premier Division matches is in the order of 40000 spectators.

Hampden Park has a large stand on the south side of the ground which has a seating capacity of 10000 , a covered enclosure on the west terracing, and the rest of the ground consists of open terraces. The capacity crowds are generated by 'national' matches, including cup semifinal, final and international matches. Crowds for nine matches in 1988-1989 and 11 matches in 1989-1990 varied between 7719 and 72079. Most major matches at Hampden attract crowds of approximately 60000 .

St. Andrew's Ambulance is responsible for providing first aid at both of these venues and all casualties are logged by the 'nominated officer' who is responsible for the briefing, distribution and supervision of the first aiders in attendance at each match. 
As far as possible, minor incidents at Ibrox are dealt with at one of the corners of the ground to avoid obstructing the spectators' view of the proceedings; at Hampden a considerable amount of treatment is given on the large peripheral area of the playing surface. When necessary, casualties are transported back to the first aid room, which is located under the original main stand at both grounds.

A close liaison exists at both of these major venues with the Scottish Ambulance Service, who are responsible for transportation of casualties to the nearest hospital when necessary. The Scottish Ambulance Service provides communication of its own, and a back-up emergency vehicle is on stand-by at the ground. A recent innovation is the addition of a large tent which can be rapidly inflated and assembled on site. Its purpose is for a major disaster where it is an identifiable casualty clearing station on the playing surface. At Hampden, the first aiders on the field have their own radio communication system; at Ibrox, an additional new system has been organized.

Both grounds have St. Andrew's Ambulance Association medical personnel who are responsible for the provision of support to the first aiders who deal with problems among spectators. These medical practitioners are in addition to the club doctor, the latter being responsible for the footballers and staff of the club.

\section{Injuries at football matches}

The first aid year is documented for 12 months from April. The first aid team dealt with 180 casualties at Ibrox in 1988-1989, and 148 in 1989-1990, totalling 328 . In these 2 years, there were 440 injuries at Hampden. The total number of casualties dealt with by the first aiders at both grounds was 768 .

All casualties have been reviewed. For convenience, they have been divided into six categories. The terminology used to describe injuries is that of first aiders and not qualified medical personnel. To medical persons it may seem odd that a patient will attend a first aid post complaining of such trivia as a 'head bump', but the first aider has to respond to such complaints. It also has to be remembered that malingerers exist in football crowds, using an apparent injury as a means of changing their position within the ground.

\section{Group 1 - medical conditions}

Included in this group are pre-existing medical conditions known to the patient or developing during the course of the game, which were correctly diagnosed by the first aiders at the ground (Table 1).

As can be seen, the majority (175 of 306 ) suffered from a simple faint. There were more serious conditions, including three with heart attacks, four with angina, seven with complications of diabetes and 13 who had some impairment or distress related to the respiratory tract (seven asthmatic, four nonasthmatic breathing difficulties, one sore throat and pyrexia, and one (?hysterical) hyperventilation). The three patients who suffered a heart attack had cardiac arrests, and were given external chest compression
Table 1. Known medical conditions, conditions of a non-traumatic nature or pre-existing conditions

\begin{tabular}{|c|c|c|c|c|}
\hline & \multicolumn{2}{|c|}{ Ibrox } & \multicolumn{2}{|c|}{ Hampden } \\
\hline & $88-89$ & $89-90$ & $88-89$ & $89-90$ \\
\hline High blood pressure & 1 & - & - & - \\
\hline Chest pain/angina & - & 1 & - & 3 \\
\hline Heart attacks & 3 & - & - & - \\
\hline Hay fever & - & - & 1 & - \\
\hline Hyperventilation & 1 & - & - & - \\
\hline Breathing difficulties & 4 & - & - & - \\
\hline Faint & 30 & 20 & 40 & 85 \\
\hline Collapse & - & 3 & - & - \\
\hline Epileptic & - & 4 & 1 & 2 \\
\hline Black-out & - & 1 & - & - \\
\hline Double vision & - & 2 & - & - \\
\hline Diabetics & 2 & 2 & 1 & 2 \\
\hline Nose bleed & 4 & 4 & - & 7 \\
\hline Throat and mouth infection & 1 & - & - & 3 \\
\hline Anxiety & - & 6 & - & - \\
\hline Asthmatic & - & 2 & 2 & 3 \\
\hline Hunger & - & 1 & - & - \\
\hline Headache & - & 1 & 2 & 4 \\
\hline Toothache & - & 1 & - & - \\
\hline Pregnant women & - & - & - & 1 \\
\hline Abdominal pain & 7 & 5 & 6 & 5 \\
\hline Sting (insect) & 1 & 4 & - & - \\
\hline Swollen eyes & 1 & - & - & - \\
\hline Redress wounds & 4 & 3 & 4 & 5 \\
\hline Conjunctivitis & - & 1 & - & - \\
\hline Ingrowing toenail & - & 1 & - & - \\
\hline Sudden illness & - & 2 & - & - \\
\hline Ulcer & - & 1 & - & 1 \\
\hline Boils & - & - & 1 & - \\
\hline Effects of heat & - & - & - & 3 \\
\hline Total & 59 & 65 & 58 & 124 \\
\hline
\end{tabular}

and artificial ventilation by the first aiders before being passed to the ambulance services for transport to the nearest hospital. Two of these patients were dead on arrival and one recovered. The seven diabetic patients had suffered hypoglycaemic attacks and were given sugar and sweet drinks which resulted in a rapid recovery without further complications. They were advised to contact their general practitioners when they returned home. The four subjects with breathing difficulties were treated in the first aid room and returned to their homes.

Table 2. Subjects with suspected fractures or dislocations

\begin{tabular}{|c|c|c|c|c|}
\hline & \multicolumn{2}{|c|}{ Ibrox } & \multicolumn{2}{|c|}{ Hampden } \\
\hline & $88-89$ & $89-90$ & $88-89$ & $89-90$ \\
\hline Nose & 1 & 1 & 2 & 1 \\
\hline Jaw (D) & - & 1 & - & - \\
\hline Clavicle & - & - & - & 2 \\
\hline Shoulder (D) & - & - & - & 1 \\
\hline Arm & - & - & - & 1 \\
\hline Elbow & - & - & - & 2 \\
\hline Wrist & 3 & - & - & - \\
\hline Hand & - & 1 & - & 1 \\
\hline Finger (D) & - & 1 & - & - \\
\hline Leg & - & - & 2 & - \\
\hline Ankle & 1 & 3 & - & - \\
\hline Foot & 1 & - & - & - \\
\hline Total & 6 & 7 & 4 & 8 \\
\hline
\end{tabular}

D = Dislocation 


\section{Group 2 - suspected fractures or dislocations}

In large crowds using long steep staircases, falls are inevitable and in 22 subjects the first aiders considered that a potential fracture had occurred (Table 2).

In the subjects with suspected fractures, five were confirmed on X-ray at the local hospital. There were three dislocations.

\section{Group 3 - lacerations}

There were 125 subjects overall who suffered from lacerations: of these the most common were lacerations of the face (25) and head (38) (63 of 125) (Table 3). All of these were simple lacerations which were treated by the first aiders.

\section{Group 4 - strains, 'sprains' and non-specific skeletal injuries}

This group of 190 subjects constituted the major group of injuries and the vast majority (170 of 190) involved injuries to the lower limbs, usually caused by minor falls occasioned by jumping up and down in a state of excitement resulting in loss of balance (Table 4 ). Some of these subjects sustained their injury on the approaches to the grounds.

\section{Group 5-miscellaneous injuries}

This is a group of 83 miscellaneous injuries where the majority constituted minor bruises, abrasions or minor head injuries. The abrasions were various in character and site (Table 5).

Table 3. Sites of lacerations

\begin{tabular}{|c|c|c|c|c|}
\hline & \multicolumn{2}{|c|}{ Ibrox } & \multicolumn{2}{|c|}{ Hampden } \\
\hline & $88-89$ & $89-90$ & $88-89$ & $89-90$ \\
\hline Head & - & 6 & 5 & 27 \\
\hline Face & 12 & - & 12 & 1 \\
\hline Elbow & - & - & - & 1 \\
\hline Hand & - & - & 10 & 18 \\
\hline Fingers & 3 & 7 & - & 5 \\
\hline Knee & 1 & 1 & 1 & 3 \\
\hline Leg & 1 & - & 3 & 6 \\
\hline Foot & - & - & 1 & 1 \\
\hline Total & 17 & 14 & 32 & 62 \\
\hline
\end{tabular}

Table 4. Injuries of the musculoskeletal system

\begin{tabular}{lcccccc}
\hline & \multicolumn{2}{c}{ lbrox } & & \multicolumn{2}{c}{ Hampden } \\
\cline { 2 - 3 } \cline { 6 - 7 } & $88-89$ & $89-90$ & & $88-89$ & $89-90$ \\
\hline Back injury (unspecified) & 2 & - & & - & 5 \\
Arm & - & 1 & & - & - \\
Hand & - & - & & 1 & 2 \\
Wrist & - & 4 & & - & - \\
'Stave of fingers' & 6 & - & & - & - \\
Knee & - & - & & 2 & 1 \\
Leg & 10 & 6 & & 1 & - \\
Ankle & 18 & 26 & & 46 & 61 \\
Total & 36 & 37 & & 48 & 69 \\
\hline
\end{tabular}

Group 6 - Injuries related to the ground or services within the ground

In this group are classified those patients with scalds (35) which resulted from spillage of containers of hot liquids. There were only six cases where the subject had been crushed against a wall, barrier or a fence or some such rigid object within the ground (Table 6).

\section{Site within the ground}

Apart from recording the actual injuries, the nominated officer at Ibrox made as accurate a record as possible of the location within the ground where the casualty was first encountered. The site of injury is shown in Table 7. The figures emphasize several points. At Ibrox, the majority of casualties occurred in the standing enclosure. At Hampden, all the casualties occurred in the standing areas.

\section{Equipment and training - action taken}

It was decided to ensure that basic equipment at all senior grounds in Scotland would be identical so that a first aider could transfer from one first aid room to another. Crowds are clearly variable and it is felt that the first aiders should have the assurance of knowing

Table 5. Miscellaneous injuries

\begin{tabular}{lrrrrrr}
\hline & \multicolumn{2}{c}{ Ibrox } & & \multicolumn{2}{c}{ Hampden } \\
\cline { 2 - 3 } \cline { 6 - 7 } & $88-89$ & $89-90$ & & $88-89$ & $89-90$ \\
\hline Bruising (misc.) & 13 & 9 & & - & 1 \\
Head 'bumps' & 15 & - & & - & - \\
Abrasions & 13 & 4 & & - & - \\
Injury or foreign body in eye & 3 & 4 & & 3 & 12 \\
Stood on nail & 1 & - & & - & - \\
Blow on nose & - & 1 & & - & - \\
Concussion & - & - & & - & 2 \\
Blisters (heel) & - & - & & - & 2 \\
Total & 45 & 18 & & 3 & 17 \\
\hline
\end{tabular}

Table 6. Ground-related injuries

\begin{tabular}{lrrrrrr}
\hline & \multicolumn{2}{c}{ Ibrox } & & \multicolumn{2}{c}{ Hampden } \\
\cline { 2 - 3 } \cline { 6 - 6 } & $88-89$ & $89-90$ & & $88-89$ & $89-90$ \\
\hline Scalds & 12 & 6 & & 7 & 10 \\
Crushing & 5 & 1 & & - & - \\
\hline
\end{tabular}

Table 7. Site within the ground where injury occurred

\begin{tabular}{lrr}
\hline Site & \multicolumn{2}{c}{ lbrox } \\
\cline { 2 - 3 } & $88-89$ & $89-90$ \\
\hline Enclosure & 110 & 75 \\
Main stand & 12 & 35 \\
Broomloan stand (visitors) & 15 & 16 \\
Copeland Road stand & 7 & 12 \\
Govan stand (largest stand) & 16 & 5 \\
Approaches/surrounding area & 20 & 5 \\
Total & 180 & 148 \\
\hline
\end{tabular}


exactly what equipment would be standard in any first aid room where he or she was asked to work.

The basic equipment within the first aid room at all major grounds is shown in Table 8. The cost was met by the Scottish Football Trust and the Scottish League; each Premier Division ground received the basic first aid box plus two York type trolleys. The York trolley allows the first aider to place a casualty in a modified recovery position with head-down tilt when necessary. It also allows the first aider to commence treatment on the trolley and to be able to continue it during transportation. At clubs playing in the lower divisions, one trolley was supplied.

At all grounds a portable resuscitation kit consisting of an Ambu bag (Ambu, Denmark), laryngoscope, endotracheal tube and portable suction apparatus supplied for use by the doctor responsible for crowd safety. Steps are being taken to standardize the individual first aid bags carried by St. Andrew's Ambulance personnel.

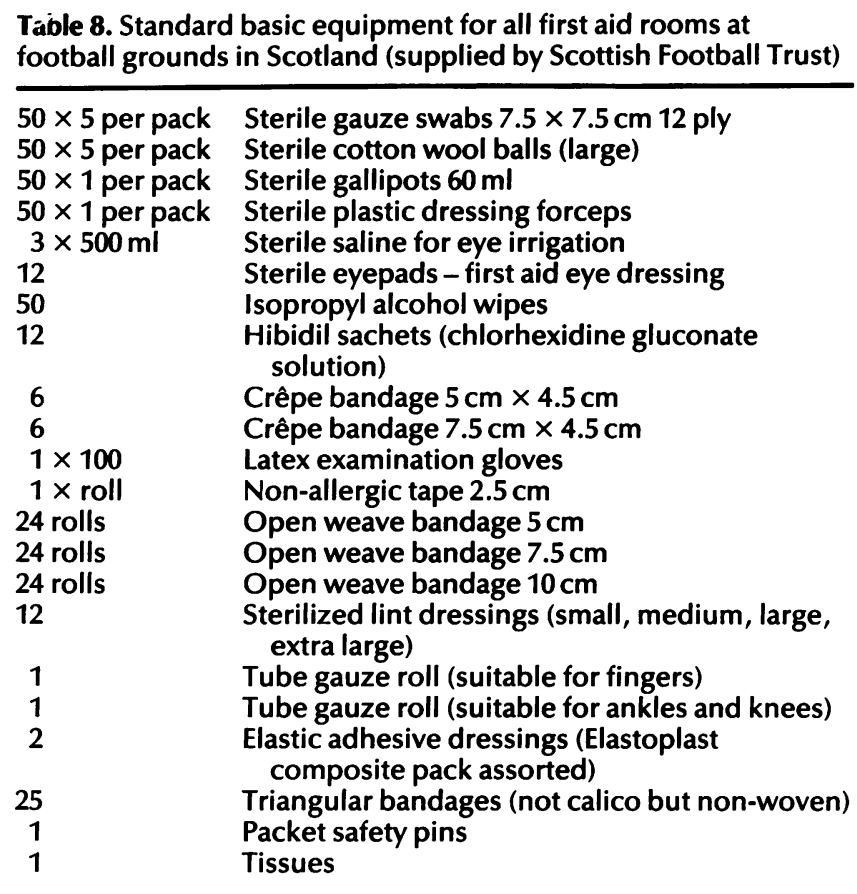

In addition to the regular company type exercises which allow first aiders to become familiar with transportation techniques, a new series of regular exercises has been initiated which helps the first aiders to cope with individual and mass casualty situations. One senior medical member of the St. Andrew's Ambulance Association has systematically visited grounds during the playing season to inspect the facilities and to advise and discuss the first aid provision with the regular first aiders. Encouragement has been given to the local groups and a subcommittee of the St. Andrew's Ambulance Association has regularly discussed the current training programmes and equipment with members of the organization along with interested and necessary supporting bodies, in particular the Scottish Ambulance Service.

The acquisition of radio communications, with formalized procedures added to a review of the Association command structure and response tech- niques, will greatly enhance the first aid facilities at all major football grounds with effect from the 1990-1991 season.

\section{Discussion}

Most football grounds in the UK are of very poor quality with respect to spectator safety and comfort. The sudden accumulation of a vast crowd of excited people at a match always has disaster potential. There is a parallel between football grounds and old industrial plants where it is recognized that drastic improvements cannot be made to old structures. Further problems may arise from the locality of old buildings since local developments may have hampered access not only for crowds but for emergency services. This applies particularly to old football grounds.

The city of Glasgow has had several major disasters, including the Ibrox disaster of $1971^{2}$. Examination of the reports of this particular event confirms that nine of 97 casualties who reached hospitals in the area were dead on arrival and it is probable that more than 97 were injured but did not report for medical attention. This report, combined with the report of the Working Party ${ }^{3}$ formed by the Board in 1971, indicated certain specific problems related to the disaster:

1. Communications were likely to be a major problem, especially if hospital switchboards become jammed by calls from anxious relatives.

2. The time scale of the incident would almost inevitably mean that a senior medical officer may not reach the site quickly enough to control medical services.

3. There was an almost unrecognized danger to casualties who were injured but not immobilized in that they could become more seriously injured because of crowd pressure.

To help minimize such problems, it is essential that medical personnel, including first aiders, understand the concept of triage. In addition, imaginative and repeated training exercises are required so that all concerned may be expected to react in a controlled and disciplined manner in the event of a major calamity. The reduced number of 'incidents' in seated as compared to standing areas in grounds is clearly shown (Table 7), and confirms the concept of the all-seated stadium as advocated by Lord Taylor.

It is interesting that in the recently completed World Cup series, where crowds of over 60000 were commonplace, no major accidents occurred. As far as could be seen, the crowds attending such matches approached the venue in a relaxed and orderly manner, which was probably related to a guaranteed and numbered seat.

\section{References}

1 Lord Taylor. The Hillsborough Disaster 15th April 1989, London: HMSO CM962: 1990.

2 Major accidents: Report of working party established by Western Regional Hospital Board following the Ibrox disaster. Western Regional Hospital Board, 1971.

3 Report of working party by Western Regional Hospital Board (Scotland) following the Ibrox disaster. Glasgow: Civic Press Glasgow, 1971 